\title{
Determination of the influence of adherent surface on the adhesive bond strength
}

\author{
Tomas Kalina ${ }^{1, *}$, Frantisek Sedlacek ${ }^{1}$, Jan Krystek $^{2}$ \\ ${ }^{1}$ RTI - Regional Technological Institute, Faculty of Mechanical Engineering, University of West \\ Bohemia, Univerzitní 8, 30614 Pilsen, Czech Republic. \\ ${ }^{2}$ European Centre of Excellence, NTIS - New Technologies for Information Society, Faculty \\ of Applied Sciences, University of West Bohemia, Technicka 8, 30100 Pilsen, Czech Republic
}

\begin{abstract}
A type of surface and a surface treatment of the adherends has a great influence on strength and durability of bonded joints. This paper deals with an experimental testing of influence of adherent surface on bonded joints strength. Several combinations of materials, surface treatments and two types of adhesives has been designed and manufactured. Those properties were tested on the lap-joints. Samples were made according to the standard ASTM D5868. The materials used were steel S355, aluminium alloy EN AW 7075 T6, carbon fibre laminate and glass fibre laminate. The surface treatments used were: Sandblasted, Mechanically roughened, Anodised, Cataphoretically painted and No-surface treatment. The experimental tests of test specimens were done on the Zwick/Roell Z050 machine. Suitable combinations of material, adhesives and surface treatments were selected based on testing.
\end{abstract}

Keywords: Adherend Surface, Surface treatment, Adhesive bond, lap-joint, ASTM D5868

\section{Introduction}

Composite materials are becoming more and more used materials not only in aerospace and automotive industries but also in other industrial sectors where a high strength and stiffness at low weight is required.

In aerospace and automotive industries the fiber reinforcement composite materials are most frequently used. For joining of those composite materials with metals the adhesive bond is most frequently the best.

Within our research we are designing the metodology of predicting the strength of bonded composite material with metals when designing their structure. With the use of experimental testing and numerical simulations. In practice this methodology should be simply applicable to the majority of real components.

The overall quality of the adhesive bond is influenced by many factors. To the most significant ones belongs: the material of adhesive components [1,2], the surface treatment of adhesive areas [1, 2], the quality of degreasing of adhesive areas, the type of

* Corresponding author: tkalina@rti.zcu.cz

Reviewers: Jan Krmela, Janusz Mielniczuk 
adhesive [1, 2], the thickness of adhesive layer [1, 2], the technology of adhesion, etc. And just the material of adhesive components and the surface treatment of adhesive areas are the most important. Therefore this article is focused on this two factors. But there exists an inexhaustible quantity of combinations of adhesive materials, surface treatments and adhesives. And for this reason it was necessary to focus on selected narrower part of this set.

Every adhesive has different mechanical properties and different adhesion to different materials and to their surface treatments. For us to be able to design a suitable combination of „material-adhesive-surface treatment" we have to consider the influence of cohesion and adhesion to a particular material. For effective and objective design we create the databases of mechanical properties of adhesives, materials and surface treatments.

The goal of this article is to determine the adhesive properties of adhesive for the most commonly bonded materials in the automotive industry. The evaluation will be done not only from technical but also from economical point of view. Based on the results it will be possible, according to general assignment (adhesive areas, required load capacity, etc.) to design a suitable adhesive and surface treatment, or vice versa.

\section{Test specimens}

\subsection{Materials and adhesives}

Two epoxy structural adhesives were chosen: the adhesive Scotch-Weld DP490 and Scotch-Weld 7260 (producer 3M). These adhesives are often used in automotive industry.

Two most commonly used composite materials and two most commonly used metals were chosen. Specifically it is fiberglass, carbon fiber laminate, aluminium alloy EN AW 7075 T6 and steel (S355 J0, according to EN10025-2:2004). For these four chosen materials multiple surface treatments were designed. The effect of the surface treatment of individual materials on the adhesive properties of the glued joint was monitored.

It was considered to bond the fiberglass with aluminium alloy using the Scotch-Weld DP490 adhesive and adhesion of carbon fiber laminate with steel using the Scotch-Weld 7260 .

\subsection{Dimensions of the test samples}

Samples for shear adhesion testing were designed according to ASTM D5868 [3]. This is a Lap-joint. The dimensions of the samples and the layers of adhesive are shown in the Fig. 1.

\begin{tabular}{|l|c|c|}
\hline \multicolumn{1}{|c|}{ Name } & Parameter & $\begin{array}{c}\text { Dimension } \\
{[\mathrm{mm}]}\end{array}$ \\
\hline $\begin{array}{l}\text { Adhesive } \\
\text { thickness }\end{array}$ & $\mathrm{A}$ & 0.75 \\
\hline Specimen width & $\mathrm{B}$ & 25 \\
\hline Specimen length & $\mathrm{L}$ & 100 \\
\hline Overlap & $\mathrm{O}$ & 25 \\
\hline $\begin{array}{l}\text { Material } \\
\text { thickness }\end{array}$ & $\mathrm{T}$ & $\begin{array}{l}\text { depending on } \\
\text { the type of } \\
\text { material }\end{array}$ \\
\hline
\end{tabular}

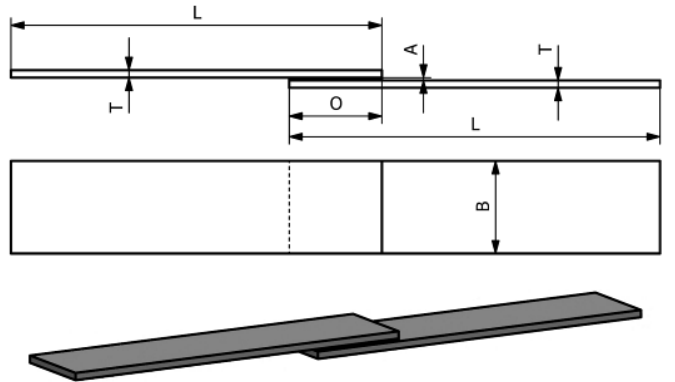

Fig. 1. Sample dimensions for adhesion detection according to the ASTM D5868 


\subsection{Preparation tool for samples adhesion}

To ensure high accuracy were the base material cut very precisely using water jet cutter machine. To achieve high bonding accuracy a product was designed preparation tool.

The construction of preparation tool is a modular design with an adjustable main plate. Therefore the preparation tool can be set for any thickness of a material and adhesive. Moreover, it is possible to set two overlap sizes of $12.5 \mathrm{~mm}$ and $25 \mathrm{~mm}$ (according to ASTM D5868 [3]). The position of the base material is determined by two auxiliary plates. The basic structure of the preparation is described in the Fig. 2.

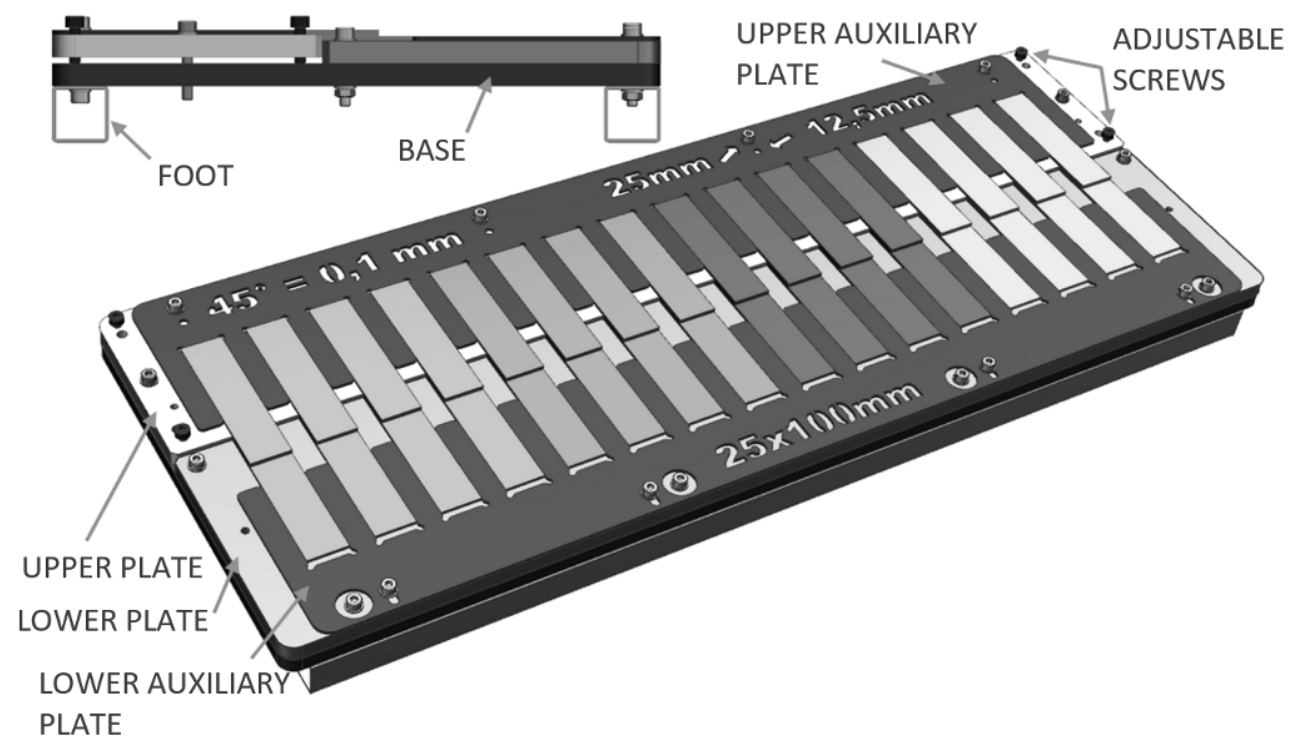

Fig. 2. Preparation tool for lap-joint samples' adhesion

\subsection{Surface treatments of the samples}

Fiberglass and carbon laminate can be used without any surface treatment or it is possible to mechanically roughen the surface. It is also possible to use various chemical treatments of adhesive surfaces by means of so called primers etc. but those products are bound to specific types of adhesives and materials used. For fiberglass and carbon laminate, only two variants have been proposed: no surface treatment and the surface mechanically roughened with P80 sandpaper.

Aluminium and steel alloys are more capable of surface preparation. For the steel and aluminium alloy, the following surface treatments have been proposed: without surface treatment (surface only degreased), abrasive blasted surface, anodized surface, cataphoretic painted surface with subsequent roughening with sanding foam.

The selected materials, surface treatments, the number and size of samples are given in Table 1. 
Table 1. Proposed samples

\begin{tabular}{|c|c|c|c|c|}
\hline Material & Surface treatment & Code & $\begin{array}{c}\text { Qty. of } \\
\text { samples [-] }\end{array}$ & $\begin{array}{l}\text { Dimension of } \\
\text { sample [mm] }\end{array}$ \\
\hline \multirow{2}{*}{ glassfiber } & without & $\mathrm{GO}$ & 4 & T1.8 - 25x100 \\
\hline & mechanically roughened** & GZ & 4 & T1.8 - 25x100 \\
\hline \multirow{2}{*}{$\begin{array}{l}\text { carbon fiber laminate } \\
\text { smooth side }\end{array}$} & without & $\mathrm{KHO}$ & 4 & T2.5 - 25x100 \\
\hline & mechanically roughened $* *$ & KHZ & 4 & T2.5 - 25x100 \\
\hline \multirow{2}{*}{$\begin{array}{l}\text { carbon fiber laminate } \\
\text { wrinkled side }\end{array}$} & without & KDO & 4 & T2.5 - 25x100 \\
\hline & mechanically roughened ${ }^{* *}$ & KDZ & 4 & T2.5 - 25x100 \\
\hline \multirow{4}{*}{$\begin{array}{l}\text { aluminium alloy } \\
\text { EN AW } 7075\end{array}$} & without & $\mathrm{HO}$ & 4 & T2 $-25 \times 100$ \\
\hline & abrasive blasted & HP & 4 & T2 $-25 \times 100$ \\
\hline & anodized & $\mathrm{HE}$ & 4 & T2 $-25 \times 100$ \\
\hline & cataphoretic painted* & HK & 4 & T2 - 25x100 \\
\hline \multirow{4}{*}{ steel S355 } & without & $\mathrm{OO}$ & 4 & T1.5 - 25x100 \\
\hline & mechanically roughened** & $\mathrm{OZ}$ & 4 & T1.5 - 25x100 \\
\hline & abrasive blasted & $\mathrm{OP}$ & 4 & T1.5 - 25x100 \\
\hline & cataphoretic painted* & $\mathrm{OK}$ & 4 & T1.5 - 25x100 \\
\hline
\end{tabular}

* with subsequent roughening with sanding foam

**with P80 sandpaper

\section{Experimental testing}

Experimental testing of samples was performed on the Zwick / Roell Z050 machine. It is a static materials testing machines with a maximum pulling force of $50 \mathrm{kN}$, equipped with extensometers and several types of jaws.

Lap-joint samples were clamped directly into the jaws of the machine. The difference between the bottom and the top of the sample was eliminated by moving the upper jaw axes relative to the lower jaw. Samples were clamped into jaws, always $25 \mathrm{~mm}$ in length on each side. The distance between the jaws was set to $125 \mathrm{~mm}$. The distance between the arms of the strain gauges was set to $80 \mathrm{~mm}$.

Lap-joint samples were loaded by pulling. The testing happened quasi-statically. The speed of jaws's shift was set to $13 \mathrm{~mm} / \mathrm{min}$ according to ASTM D5868 [26]. In this measurement, the loading force $[\mathrm{N}]$ and the deformation $[\mathrm{mm}]$ of the samples were subtracted using extensometers.

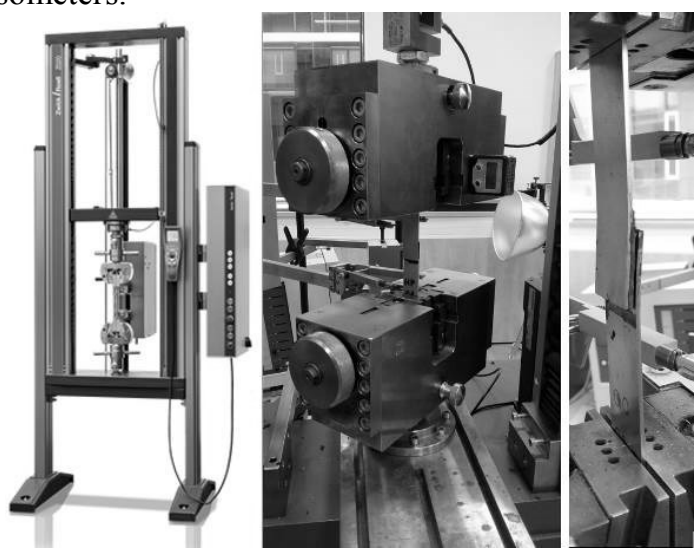

Fig. 3. Static materials testing machines - Zwick/Roell Z050 


\section{Evaluation of tests}

There is evaluated mainly maximum force to failure of the joint recalculated to average shear strength. Respectivelly, comparison of average shear strength for different surfaces. The deformation is relevant here, and is significantly affected by the properties of the bonded material.

\section{Fiberglass samples}

Samples were made of pre-preg ("pre-impregnated" composite fibers) HexPly® M49/32\%/600S8/GE-300. The composition of textile weave is of $8 \mathrm{H}$ satin type. The nominal area weight of this material is $882 \mathrm{~g} / \mathrm{m}^{2}$. Tensile strength $X_{T}=550 \mathrm{MPa}$. The laminate layout is formed by alternating 0 and $45^{\circ}$, so that the resulting layout was symmetrical.

The geometric parameters of the base material and final samples can be seen in Fig. 1 and Table 1.

The samples from fiberglass were glued using adhesive Scotch-Weld DP490. Measured values from experimental testing can be seen in Fig. 4. Resulting average shear strength and its comparison for fiberglass can be seen in Table 2.
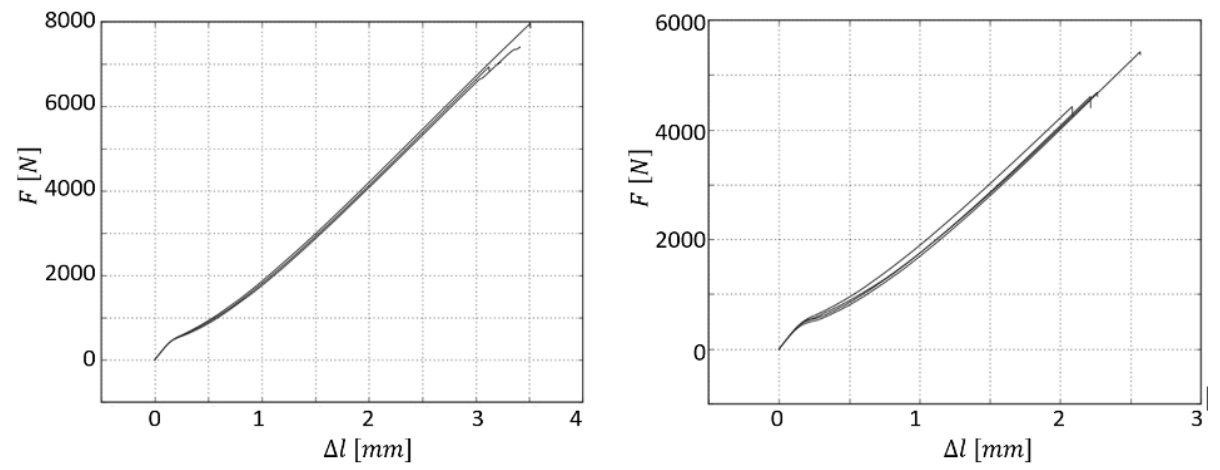

Fig. 4. Measured values from experimental testing for fiberglass a) $G O$ - without surface treatment, b) GZ-mechanically roughened

Table 2. Results and comparison for fiberglass

\begin{tabular}{|l|l|c|c|c|}
\hline \multirow{2}{*}{ Material } & \multirow{2}{*}{ Surface treatment } & \multirow{2}{*}{ Code } & Average load & Average shear strength \\
\cline { 4 - 5 } & & $\mathbf{F}_{\mathbf{A}}[\mathbf{N}]$ & $\tau$ SA [MPa] \\
\hline \multirow{2}{*}{ glassfiber } & without & GO & 7448 & $\mathbf{1 1 . 9}$ \\
\cline { 4 - 5 } & mechanically roughened** & GZ & 4794 & $\mathbf{7 . 7}$ \\
\hline
\end{tabular}

* with subsequent roughening with sanding foam

**with P80 sandpaper

With all the samples there occured a adhesion crack of an adhesive bond. Test specimen details after the test can be seen in Fig. 5. 

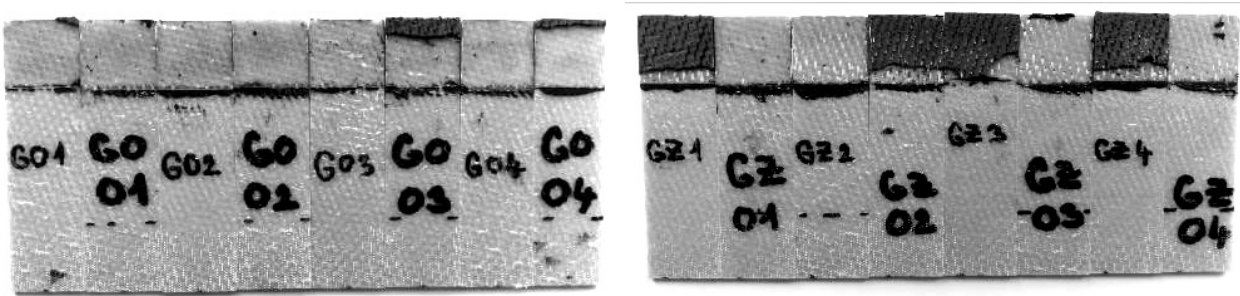

Fig. 5. Test specimen details from fiberglass after the test

\section{Carbon fiber laminate samples}

Samples were made of MTM57/CF3202VQ pre-preg. The composition of textile weave is of Twill $2 \times 2$ type. The nominal area weight of this material is $245 \mathrm{~g} / \mathrm{m}^{2}$. Tensile strength $X_{T}=709 \mathrm{MPa}$. The laminate layout is formed by alternating 0 and $45^{\circ}$, so that the resulting layout was symmetrical.

The geometric parameters of the base material and final samples can be seen in Fig. 1 and Table 1.

The specimens from carbon fiber laminate were glued using adhesive Scotch-Weld 7260. With these samples both sides (the smooth one as well as the wrinkled one due to stripping foil) were tested. Measured values from experimental testing can be seen in Fig. 6. Resulting average shear strength and its comparison for carbon fiber laminate can be seen in Table 3.
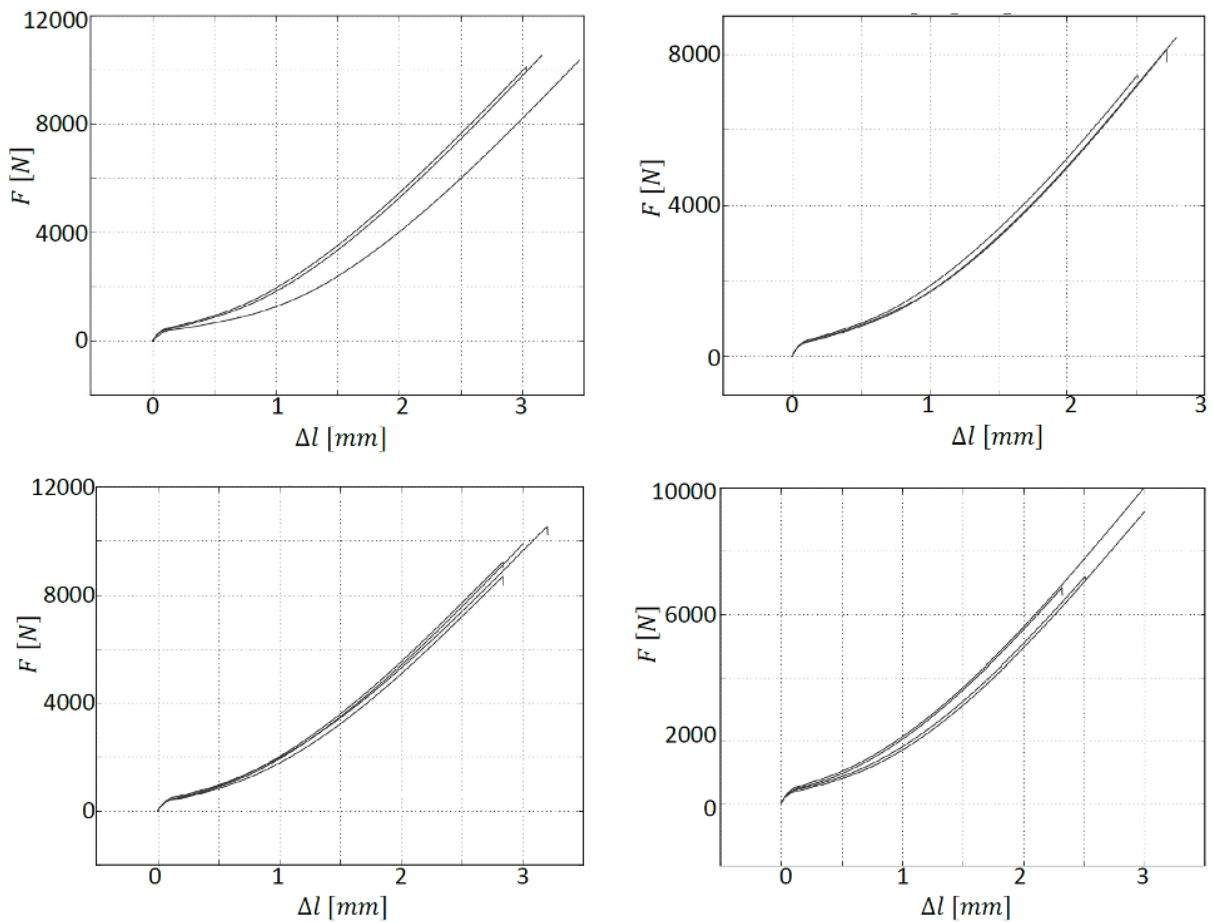

Fig. 6. Measured values from experimental testing for carbon fiber laminate

a) $\mathrm{KHO}$ - smooth side without surface treatment, b) $\mathrm{KHZ}$ - smooth side mechanically roughened, c) $K D O$ - wrinkled side without surface treatment, d) KDZ - wrinkled side mechanically roughened 
Table 3. Results and comparison for carbon fiber laminate

\begin{tabular}{|l|l|c|c|c|}
\hline \multirow{2}{*}{ Material } & \multirow{2}{*}{ Surface treatment } & \multirow{2}{*}{$\begin{array}{c}\text { Average } \\
\text { load }\end{array}$} & $\begin{array}{c}\text { Average shear } \\
\text { strength }\end{array}$ \\
\cline { 4 - 5 } & & $\mathbf{F}_{\mathbf{A}}[\mathbf{N}]$ & $\tau$ SA [MPa] \\
\hline $\begin{array}{l}\text { carbon fiber laminate } \\
\text { smooth side }\end{array}$ & without & KHO & 10343 & $\mathbf{1 6 . 5}$ \\
\cline { 3 - 5 } $\begin{array}{l}\text { carbon fiber laminate } \\
\text { wrinkled side }\end{array}$ & mechanically roughened** & KHZ & 8013 & $\mathbf{1 2 . 8}$ \\
\cline { 2 - 5 } & mechanically roughened** & KDO & 9602 & $\mathbf{1 5 . 4}$ \\
\hline
\end{tabular}

**with P80 sandpaper

With all the samples there occured a adhesion crack of an adhesive bond. Test specimen details after the test can be seen in Fig. 7. The rest of the glue with the teared fibers from carbon fiber laminate can be seen in Fig. 8.
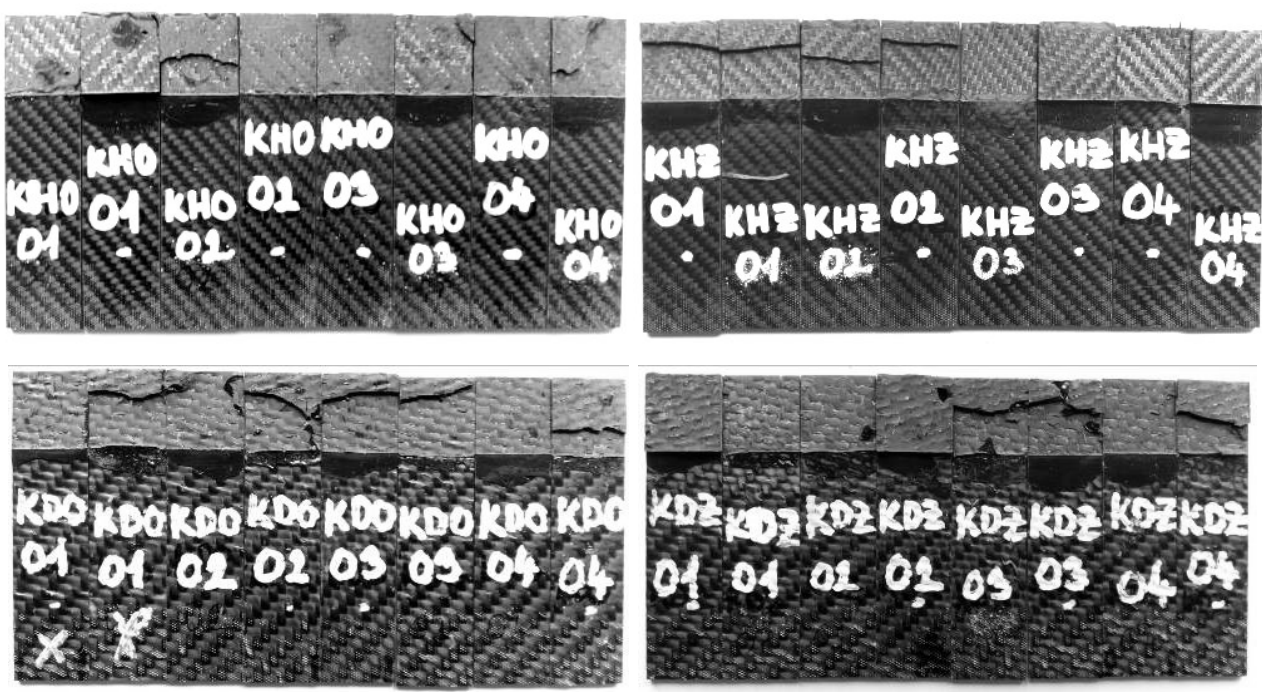

Fig. 7. Test specimen details from carbon fiber laminate after the test

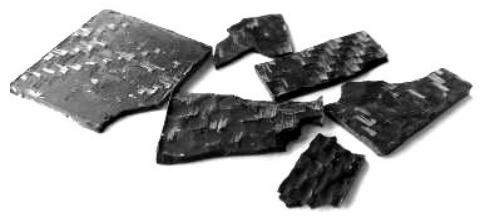

Fig. 8. The rest of the glue with the teared fibers from carbon fiber laminate

\section{Aluminium alloy samples}

Specimens are made of sheet-metal aluminium alloy EN AW 7075 T6. Tensile strength is $530 \mathrm{MPa}$. The geometric parameters of the base material and final samples can be seen in Fig. 1 and Table 1.

The specimens from aluminium alloy were glued using adhesive Scotch-WeldDP490. Measured values from experimental testing can be seen in Fig. 9 and Fig. 10. Resulting average shear strength and its comparison for aluminium alloy can be seen in Table 4 . 

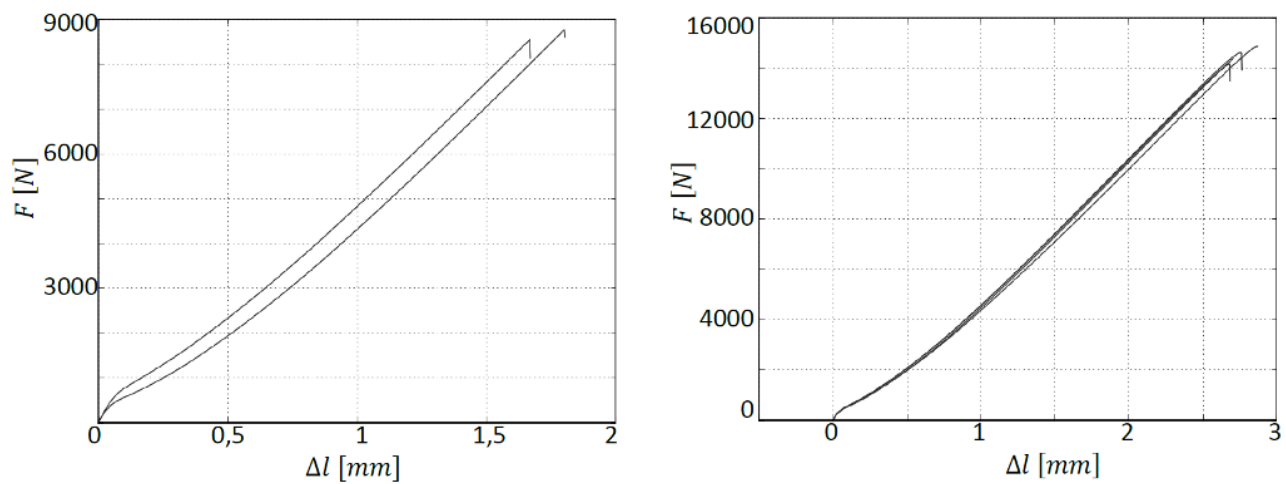

Fig. 9. Measured values from experimental testing for aluminium alloy

a) $\mathrm{HO}$ - without surface treatment, b) $\mathrm{HP}$ - abrasive blasted
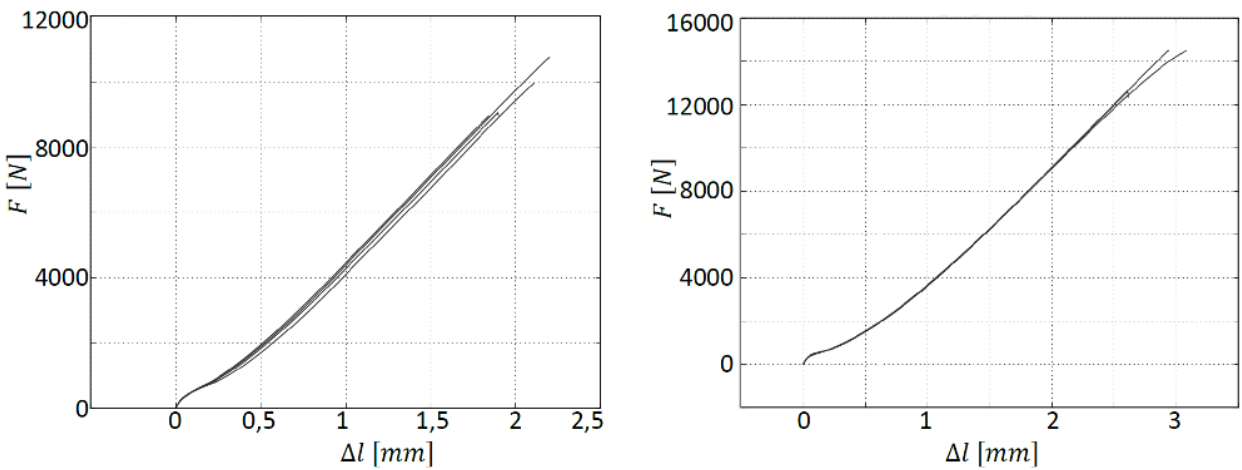

Fig. 10. Measured values from experimental testing for aluminium alloy c) $H E$ - anodized, d) $H K$ - cataphoretical painted

Table 4. Results and comparison for aluminium alloy

\begin{tabular}{|l|l|c|c|c|}
\hline \multirow{2}{*}{ Material } & Surface treatment & \multirow{2}{*}{ Code } & Average load & $\begin{array}{c}\text { Average shear } \\
\text { strength }\end{array}$ \\
\cline { 4 - 5 } & & & $\mathbf{F}_{\mathbf{A}}[\mathbf{N}]$ & $\tau$ SA [MPa] \\
\hline \multirow{3}{*}{ aluminium alloy } & without & HO & 8673 & $\mathbf{1 3 . 9}$ \\
\cline { 2 - 5 } EN AW 7075 & abrasive blasted & HP & 14532 & $\mathbf{2 3 . 3}$ \\
\cline { 2 - 5 } & anodized & HE & 9686 & $\mathbf{1 5 . 5}$ \\
\cline { 2 - 5 } & cataphoretic painted* & HK & 13879 & $\mathbf{2 2 . 2}$ \\
\hline
\end{tabular}

* with subsequent roughening with sanding foam

With all the samples there occured a adhesion crack of an adhesive bond. Test specimen details after the test can be seen in Fig. 11. The rest of the glue with the peeled anodized ply from aluminium alloy can be seen in Fig. 12. 

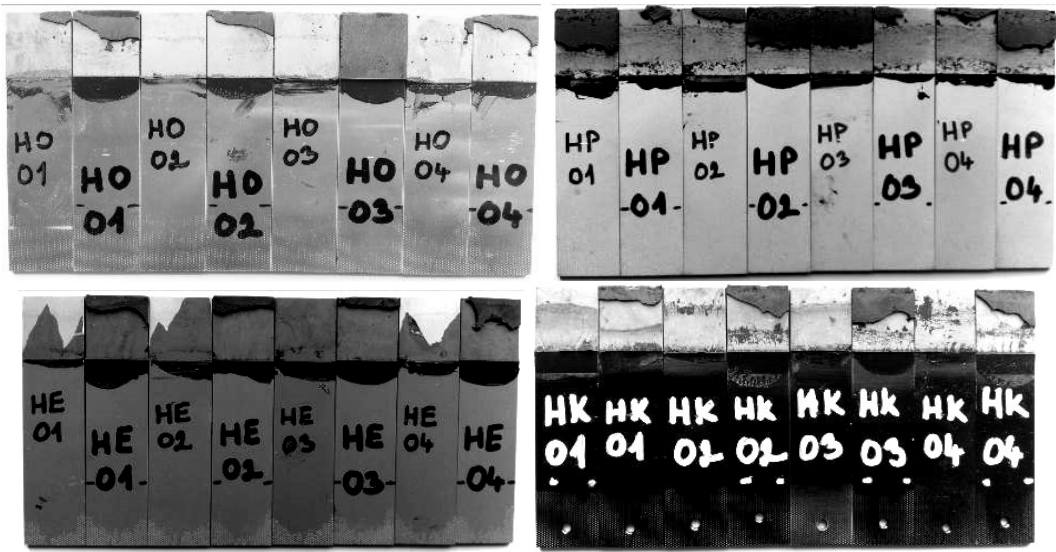

Fig. 11. Test specimen details from aluminium alloy after the test
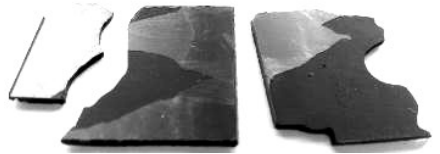

Fig. 12. The rest of the glue with the peeled anodized ply from aluminium alloy

\section{Steel samples}

Specimens are made of steel S355 J0. Tensile strength is $550 \mathrm{MPa}$. The geometric parameters of the base material and final samples can be seen in Fig. 1. and Table 1.

The specimens from steel were glued using adhesive Scotch-Weld 7260. Measured values from experimental testing can be seen in Fig. 13. Resulting average shear strength and its comparison for steel can be seen in Table 5.
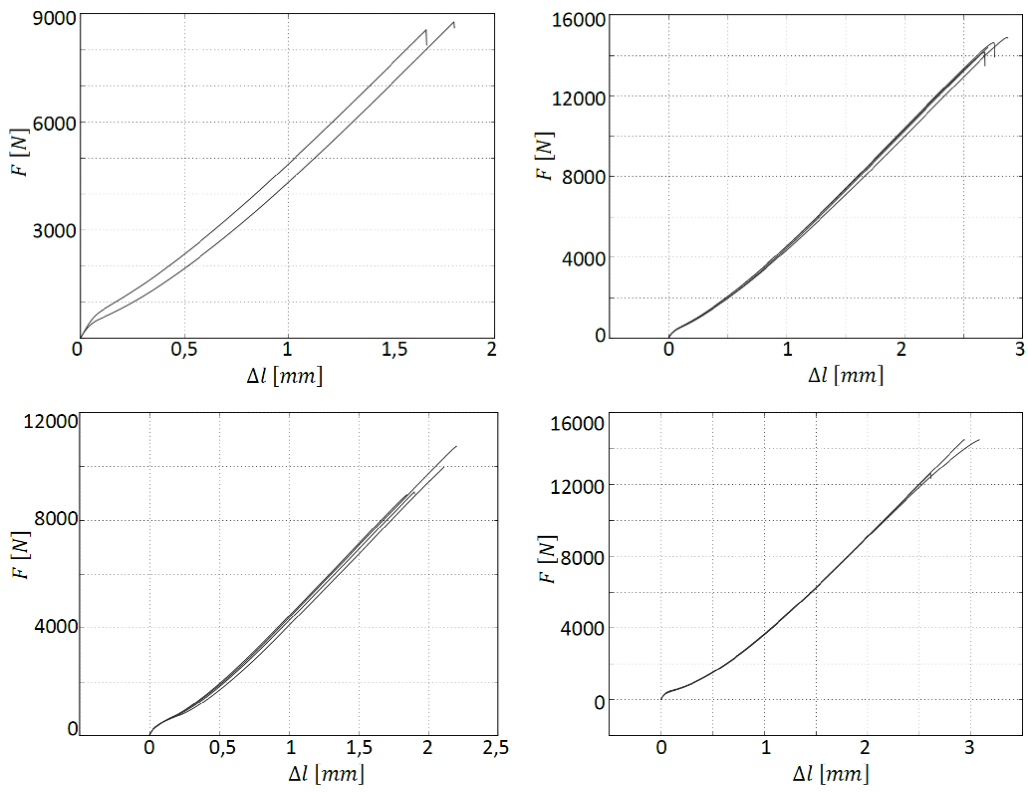

Fig. 13. Measured values from experimental testing for steel

a) $\mathrm{OO}$ - without surface treatment, b) $\mathrm{OZ}$ - mechanically roughened,

c) $O P$-abrasive blasted, d) $O K$ - cataphoretical painted 
Table 5. Results and comparison for steel

\begin{tabular}{|l|l|c|c|c|}
\hline \multirow{2}{*}{ Material } & \multirow{2}{*}{ Surface treatment } & \multirow{2}{*}{ Code } & Average load & $\begin{array}{c}\text { Average shear } \\
\text { strength }\end{array}$ \\
\cline { 4 - 5 } & & & $\mathbf{F}_{\mathrm{A}}[\mathbf{N}]$ & $\tau$ SA [MPa] \\
\hline \multirow{4}{*}{ steel S355 } & without & OO & 6357 & $\mathbf{1 0 . 2}$ \\
\cline { 2 - 5 } & mechanically roughened & OZ & 7771 & $\mathbf{1 2 . 4}$ \\
\cline { 2 - 5 } & abrasive blasted & OP & 7853 & $\mathbf{1 2 . 6}$ \\
\cline { 2 - 5 } & cataphoretic painted* & OK & 6453 & $\mathbf{1 0 . 3}$ \\
\hline
\end{tabular}

* with subsequent roughening with sanding foam

**with P80 sandpaper

With all the samples there occured a adhesion crack of an adhesive bond. Test specimen details after the test can be seen in Fig. 14.
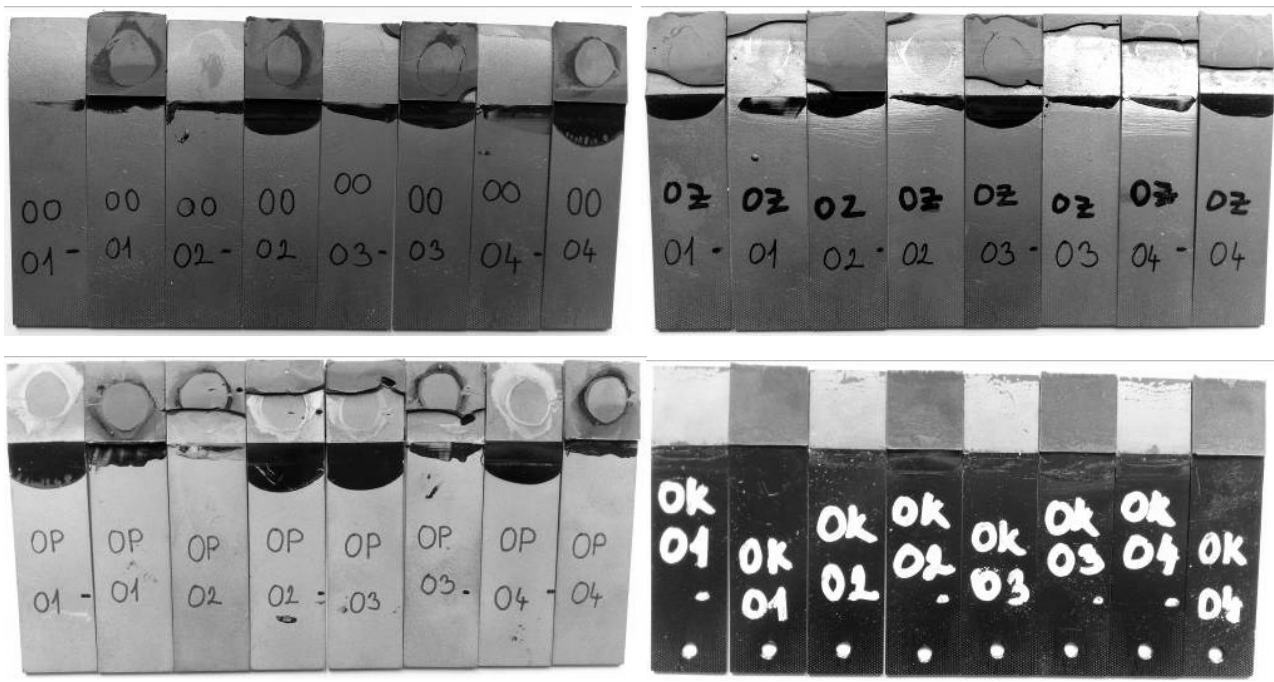

Fig. 14. Test specimen details from steel after the test

\section{Summaries}

There is evaluated mainly maximum force to failure of the joint recalculated to average shear strength. Respectively, comparison of average shear strength for different surfaces. The deformation is relevant here, and is significantly affected by the properties of the bonded material.

No purely cohesive damage occurred in any of the tests. This implies that the cohesive is very strong and that it is likely that the glue adhesion to the glued material will probably be the weak point of the glued joint using this adhesive.

Resulting average shear strength and its comparison for all tested material and for all tested surface treatments can be seen in Table 6 .

In general, we would expect that by roughening the surface will increase adhesive strength. However, this may not always be true. Based on several studies (eg $[4,5,6]$, etc.), it appears that for different materials there is a differently high value of optimum roughness to achieve the maximum strength of the bonded joint. When this limit is exceeded, the strength of the glued joint is again decreased. For example, here [5] is an optimum roughness for bonded steel samples ranging from $\mathrm{Ra}$ of 0.37 to $0.48 \mu \mathrm{m}$ obtained by grain 
sanding paper 400. Or Budhe [4] provides an optimum surface roughness for the bonding of aluminum alloy specimens of $\mathrm{Ra}=1.68 \pm 0.14 \mu \mathrm{m}$.

Based on the above, we can justify why in our tests reach roughened samples of the composite materials of less strength than samples without mechanical roughening. For the roughening of samples from composite materials, the relatively thick P80 paper was used here. With this rough sanding paper, the matrix was significantly distorted to the fibers and this allowed the material to be easily pulled out of the material. We can see that the samples without surface treatment did not demage the matrix. However, samples without surface treatment achieve higher average shear strength.

Therefore, it can not be concluded from these results that the roughened surface of the laminate leads to a decrease in strength. To find the optimum roughness of the material, a large number of samples with a finely graded roughness needs to be produced. We should probably find the roughness of the surface of the laminate at which the strength of the glued joint would be higher than that of the cleaned samples. On the basis of the optimum roughness of other materials, it can be assumed that the laminate should achieve less roughness than that obtained on the current samples. Opinions about the optimum roughness of the laminate are different in the literature $[1,2,4,5,6]$ but are most often recommended for $\mathrm{P} 150-\mathrm{P} 400$ grain papers.

In Table 6 is a comparison of the strength of the glued joint for various aluminum alloy surface treatments. The measured values show that the highest shear strength achieved sandblasted samples. This is a low-cost surface treatment, but the surface of the material is not protected from environmental influences. If it is desired to protect the bonded material against the influence of the surrounding area, it is more appropriate to use a cataphoretic painted material. It is also a relatively low-cost surface treatment, which also protects the part against corrosion and other environmental influences. The next one is an anodized sample that achieves a 30\% lower strength than a cataphoretic painted samples but can be chosen for aesthetic reasons, for example. The lowest strength is achieved by the sample of only degreased aluminum without surface treatment.

The last of the tested materials is steel. Average shear strength of surface treatment of steel is lower than for samples of aluminium alloy. The highest strength is achieved by abrasive blastedand mechanically abraded samples. Almost identical strength reaches samples without surface treatment and cataphoretic painted samples.

The above results show that the cataphoretic painting has less adhesion to steel than to the aluminum alloys. For both metals, the paint layer was detached (i.e., adhesion of the adhesive to the lacquer is higher than the adhesion of the paint to the material.) However, the thickness of the steel sample varnish requires significantly less force than the aluminum alloy sample. 
Table 6. Overall results of adhesion average shear strength

\begin{tabular}{|c|c|c|c|c|}
\hline \multirow{2}{*}{ Material } & \multirow{2}{*}{ Surface treatment } & \multirow{2}{*}{ Code } & Average load & Average shear strength \\
\hline & & & $\mathbf{F}_{\mathbf{A}}[\mathbf{N}]$ & $\tau \mathbf{S A}[\mathbf{M P a}]$ \\
\hline \multirow{2}{*}{ glassfiber } & without & GO & 7448 & 11.9 \\
\hline & mechanically roughened** & GZ & 4794 & 7.7 \\
\hline \multirow{2}{*}{$\begin{array}{l}\text { carbon fiber laminate } \\
\text { smooth side }\end{array}$} & without & $\mathrm{KHO}$ & 10343 & 16.5 \\
\hline & mechanically roughened $* *$ & $\mathrm{KHZ}$ & 8013 & 12.8 \\
\hline \multirow{2}{*}{$\begin{array}{l}\text { carbon fiber laminate } \\
\text { wrinkled side }\end{array}$} & without & KDO & 9602 & 15.4 \\
\hline & mechanically roughened $* *$ & KDZ & 8328 & 13.3 \\
\hline \multirow{4}{*}{$\begin{array}{l}\text { aluminium alloy } \\
\text { EN AW } 7075\end{array}$} & without & $\mathrm{HO}$ & 8673 & 13.9 \\
\hline & abrasive blasted & HP & 14532 & 23.3 \\
\hline & anodized & $\mathrm{HE}$ & 9686 & $\mathbf{1 5 . 5}$ \\
\hline & cataphoretic painted* & HK & 13879 & 22.2 \\
\hline \multirow{4}{*}{ steel S355 } & without & $\mathrm{OO}$ & 6357 & 10.2 \\
\hline & mechanically roughened** & $\mathrm{OZ}$ & 7771 & 12.4 \\
\hline & abrasive blasted & OP & 7853 & 12.6 \\
\hline & cataphoretic painted* & $\mathrm{OK}$ & 6453 & 10.3 \\
\hline
\end{tabular}

* with subsequent roughening with sanding foam

**with P80 sandpaper

\section{Conclusion}

Experimental testing of the adhesive properties of the most used adhesives, materials and surface treatments was carried out. Two epoxy structural adhesives were chosen: the adhesive Scotch-Weld DP490 and Scotch-Weld 7260 (producer 3M). The materials used were steel S355 J0, aluminium alloy EN AW 7075 T6, carbon fibre laminate and glass fibre laminate.

For fiberglass and carbon fiber laminate, two surface treatments have been proposed: no surface treatment and the surface mechanically roughened with P80 sandpaper. Greatest adhesion strength of both bonded composite materials were achieved with samples without surface treatment. This adhesion strength achieves values: $\tau S_{A G O}=11.9 \mathrm{MPa}$ for glassfiber, $\tau S_{A K H O}=16.5 \mathrm{MPa}$ for smooth side of carbon fiber laminate and $\tau S_{A K D O}=15.4 \mathrm{MPa}$ for wrinkled side of carbon fiber laminate.

For the steel and aluminum alloy, the following surface treatments have been proposed: without surface treatment (surface only degreased), abrasive blasted surface, anodized surface, cataphoretic painted surface with subsequent roughening with sanding foam. Greatest adhesion strength of adhesive bonds were achieved with abrasived blasted $\left(\tau S_{A H P}=23.3 \mathrm{MPa}\right)$ and cataphoretic painted $\left(\tau S_{A H K}=22.2 \mathrm{MPa}\right)$ samples from aluminium alloy EN AW 7075 T6. Greatest adhesion strength of adhesive bonds were achieved with abrasived blasted $\left(\tau_{\mathrm{S} A O P}=12.6 \mathrm{MPa}\right)$ and mechanically roughened $\left(\tau_{\mathrm{S} A o z}=12.4 \mathrm{MPa}\right)$ samples from steel S355J0. Average shear strength of surface treatment of steel is lower than for samples of aluminium alloy. Cataphoretic painting can be done on both aluminium alloy and steel. But as can be seen from the results, the adhesion of the lacquer to the steel is considerably lower.

The result is an overview of the acquired values of shear strength for particular combinations of material and surface treatment.

Based on these values, we can choose the appropriate surface treatment to provide the transfer of required force. Or, on the contrary, on the basis of the selected surface treatment, we can calculate the minimum required area of the glued joint. However, it should be emphasized that this is a simplified calculation with a equally stress assumption because in 
reality the stress in the glued joint is not constant over its entire surface. It is therefore necessary to count with sufficient safety.

The article has been prepared under project LO1502 'Development of the Regional Technological Institute' under the auspices of the National Sustainability Programme I of the Ministry of Education of the Czech Republic aimed at supporting research, experimental development and innovation.

\section{References}

1. Collective of authors, Loctite - Worlwide Design Handbook. Mainz: Erasmusdruck GmbH. 452. ISBN 0-9645590-0-5 (1998)

2. Grundlagen, Verarbeitung, Anwendungen, Faserverbundwerkstoffe Handbuch. Waldenbuch: RG Faserverbundwerkstoffe GmbH. 237. (2009)

3. ASTM International. Standard Test Method for Lap Shear Adhesion for Fiber Reinforced Plastic (FRP) Bonding. Designation: ASTM D5868-01

4. S. Budhe, A. Ghumatkar, N. Birajdar, M. D. Banea, Effect of surface roughness using different adherend materials on the adhesive bond strength. Applied Adhesion Science 2015, DOI: 10.1186/s40563-015-0050-4. (2015)

5. M. Muller, Vliv drsnosti ocelového povrchu na pevnost lepeného spoje. MM Průmyslové spektrum, Article code: 030908. (2003)

6. S. W. Lee, D. Lee, Static and Dynamic Torque Characteristic of Composite Cocured Single Lap Joint. Journal of Composite Materials 31, 2188-2201, (1997) 